\title{
Research on Cultural Development of Characteristic Towns in
}

\author{
China \\ Chengxin Wang ${ }^{1 *}$ \\ ${ }^{1}$ Shanghai University of Engineering Science, Shanghai 200000, China \\ *Chengxin Wang, E-mail: chengxinnba@163.com
}

Received: July 18, 2017

Accepted: July 29, 2017

Online Published: August 11, 2017

doi:10.22158/wjssr.v4n3p237

URL: http://dx.doi.org/10.22158/wjssr.v4n3p237

\begin{abstract}
Under the background of new-type urbanization, based on local culture, economy, science and technology, innovative-type small towns have become a major trend in social development. With the rapid development of characteristic towns in different areas, the construction of towns are also faced with many problems. For example, unitary cultural features, excessively apparent similarities, backward ideological and cultural construction have led to the lack of motive force in development, defective social benefits, and shortage of talents. As a consequence, cultural development of characteristic towns doesn't have guarantee. Sheer focus on benefits causes imbalance between economic effectiveness, cultural and social effectiveness. The lack of emphasis on scientific and technological innovation leads to the shortage of modern vitality and vigor. From the perspectives of these issues, the paper will propose relevant measures, so that cultural factors can play a better role in construction of characteristic towns.
\end{abstract}

\section{Keywords}

characteristic towns in China, cultural development, cultural industry

\section{Introduction}

With the implementation of national financial supports and relevant policies in characteristic towns, the construction and development of characteristic towns embrace new chances and challenges. Characteristic towns in different regions achieve rapid and significant development. During the process of characteristic town construction, one of the most prominent emphasis is to inherit and carry forward local and traditional culture, nurture cultural soils for creativity, liveliness and sustainability, so that local economy, science and technology can obtain constant growth and development in the fertile soil. Culture is the soul and "core" of characteristic towns. It is also the soil for vitality of small towns. They should be carefully excavated and forged. Based on the general development of various characteristic towns, they are primarily established upon the foundation of traditional cultures. In the generation of 
characteristic towns, more than $40 \%$ of them are cultural and historical towns. They also preserve rural features, cultural and historical inheritance. Therefore, cultural development research is an important entry point in studies on Chinese characteristic towns, which involves great significance to construction of characteristic towns. Incorporating cultural factors in the construction of characteristic towns should consider local and traditional cultures, seek for unique features, continue historical and cultural origins, and carry forward the essence of craft culture. Besides, it also needs to include modern factors, take a global view, and create cultural vitality through innovation. Therefore, the strategy of cultural development is an feasible approach for the construction of Chinese characteristic towns.

\section{Current Situation of Cultural Development in Chinese Characteristic Towns}

\subsection{Common Phenomenon of Unitary Cultural Features and "Culture Similarities"}

As the treasury of traditional culture, it should be relative easy to make arrangements for Chinese characteristic towns. However, in practical construction, "culture similarities" are commonly demonstrated. In this regard, cultural similarities not only refer to identical concepts of cultural development, but also similar ideas in cultural extension, such as identical appearance and furnishings of old buildings, streets with stereotyped custom and habits, common patterns of rural tourism. Such excessively "cultural similarities" may cause people to lose their interest in appreciating the culture, experiencing ecological tourism and making industrial investments in the small towns. In this regard, it is necessary to learn from the small town construction in the US. Due to emphasis on individuality and unique features, towns in the US serve as typical examples in cultural constructions. For instance, architectural appearances need to be carefully designed and planned. Road alignments and landscape arrangements also have their own unique features, aiming to highlight the special atmosphere of humanism, so that people can feel the unconventional and unusual "small town cultures".

\subsection{Concepts in Cultural Construction Are Backward. "Cultural Confidence" Is Inadequate. Motive} Force of Cultural Development Is in Shortage

"China needs to forge all-around and multi-functional characteristic towns that incorporate 'industry, culture, architecture, tourism, ecology and residence'. For central and local governments, as well as enterprises, their main problem is the conservative and backward concepts in cultural development. They aren't confident that cultural development can bright about huge changes in towns". Residents in towns also lack the awareness of cultural protection. For example, in order to gain more income, many inheritors of non-material cultural heritages abandon conventional craftsmanship with hundreds years of history. Instead, they choose to work for others in industrial parks. As a consequence, traditional cultural inheritance is interrupted. It is also one of the signs in lack of "cultural confidence". 


\subsection{Unclear Industry Position. Emphasis Economic Benefits Ignores Social Benefits}

"There are a great number and a huge variety of non-material cultural heritages in China. They enjoy a high reputation around the world. Representative traditional cultures include ancient woodblock printing techniques, traditional wood structures, the brocade weaving technique in Nanjing, celadon ware making craft in Longtime, etc." These examples of traditional culture and cultural development of Chinese characteristic towns should be supplementary to each other. Towns without cultural connotations are soulless. Characteristic town construction is also the reflection and support for traditional culture development. In this respect, one of the successful cases is the town of Longquan with celadon ware culture. The industrial position is to forge a small town with historical and classic culture, develop celadon ware culture and eco-tourism industry. As for industrial distribution, the purpose is to infiltrate "celadon ware culture" to different aspects like industrial transformation, product design, and innovations of traditional skills. Currently, the town has formed multi-directional pattern of "celadon ware industry+cultural tourism+ecological residence". It nor only promotes economic development, but also gives full play to advantages of local culture. Hence, the Chinese traditional celadon ware culture has gone global and generated favorable social benefits.

\subsection{Laws and Regulations Are Yet to Be Improved. Professional Talents Are Inadequate}

Currently, the government has achieved some progress in perfecting relevant policies for cultural construction of characteristic towns. For instance, in the start of 2016, Some Suggestions on Promoting New-Type Urbanization proposed policies in accelerating leisure tourism and folk cultural inheritance in characteristic towns. In July, it also specifies that until 2020, the goal is to develop 1000 unique and lively towns with leisure tourism, educational technology, traditional cultures and favorable living conditions. Furthermore, other regions like Zhejiang, Shanghai, Guangdong, and Shenzhen also put forward their own plans and suggestions on cultural development patterns. However, it is still far from enough to facilitate cultural development. For example, policies and suggestions on cultivating cultural industries, traditional culture inheritance, as well as combination of culture and tourism are inadequate. In addition, the shortage of professional talents in developing cultural industries and urban planning is another significant impediment in the construction of Chinese characteristic towns.

2.5 Characteristic Industry Innovation Is Insufficient. Integration of Culture, Economy, Science and Technology Is Still to Be Enhanced

In the background of knowledge society and innovation, Premier Li Keqiang proposed the development strategy of "Internet+". To put it simply, the strategy aims to make full use Internet platform and information technology, integrate Internet with other traditional industries, in order to change people's lifestyles. Hence, cultural construction of Chinese characteristic towns also needs to keep up with the trend of "Internet+". The "Internet+" of Taobao is an innovative integration of traditional market and Internet. Chinese characteristic towns need to combine regional cultures with Internet, enhance connections between characteristic industries, economy, science and technology, so as to promote the 
overall prosperity of cultural construction and development. Wuzhen, in Tongxiang, Zhejiang Province is a typical example of incorporating traditional cultures with modern economy, science and technology. In 2014, the 1st World Internet Conference was successfully held in Wuzhen. Besides, it is specified as the permanent site for World Internet Conference. Since then, when it comes to the historical and cultural town-Wuzhen, people tend to associate it with "Internet". Internet has added modern elements to the historical and cultural town, and promoted its reputation on the world stage.

\section{Countermeasures for Cultural Development of Chinese Characteristic Towns}

\subsection{Forge Small Towns' Cultural Characteristics. Focus on Diversified Development}

In the process of forging Chinese characteristic towns, it is necessary to primarily depend on urban cultures. Cultural development patterns in different regions involve both generality and individuality. We can neither preserve traditional culture in a purely complacent way, nor indiscriminately imitate the cultural development patterns in the west or other regions. "Seek common ground while reserving differences for characteristic development" should be the feasible attitude in cultural development of Chinese characteristic town. Each town should have its distinctive traits and features, so that different cultural characteristics are included in various aspects like local industries, tourism, architecture, ecology and retirement.

3.2 Focus on Inheriting and Preserving Traditional Culture. Enhance "Awareness of All People" for

\section{Cultural Construction}

Cultural development of Chinese characteristic towns are closely related to traditional culture support. Without such support, characteristic towns will be in imminent danger like trees without rainwater. In this regard, China should learn from western countries. For instance, in 1953, the UK released some laws and regulations, such as Act of Historical Buildings and Ancient Monuments Preservation, to protect historical remains, including ancient buildings and sculptures. It also set up special zones for historic reservations. For Chinese characteristic towns, cultural development should "assimilate the essence and reject the dross" from traditional cultures. Meanwhile, it is also necessary to enhance the "all people's awareness" in reserving and carrying forward traditional culture. During the 12th Five-Year Plan, the central government discusses subjects like "Focus on people's livelihood", "Increase happiness index for all people", and "Create a happy China". Excellent cultures serve as important means to enrich people's minds and souls. They are also necessary approaches to forge cultural towns with Chinese characteristics.

3.3 Perfect Policy Mechanism, Regulate Market Order, and Enhance Motive Force of Cultural Development

As the "invisible hand", market poses profound impacts on constructions of Chinese towns in the economy. During this process, effective government intervention can make up for the market adjustment mechanism, promote sustainable development of towns' economy and cultures, and protect 
public interests. Meanwhile, confused market orders will lead to the lack of motive forces for cultural development. It goes against the sustainable and healthy development of Chinese characteristic towns. "Excellent cultural ethos, profound humanistic connotations and strong competitiveness of cultural industries" should be the special features of towns with "Chinese characteristics". To sum up, in the process of promoting urbanization and cultural development in China, legal construction, innovation of mechanism and market regulations are essential factors.

3.4 Clarify Industrial Positioning, Conduct Reasonable Industrial Distribution, and Promote Development of Cultural Industries

Cultural construction of Chinese characteristic towns should involve cultural industries, and abundant cultural tourism resources. Meanwhile, it is also necessary to develop service industry, and perfect social security, such as offering favorable services for the aged, and establish more nursing homes. On the basis of reasonable industrial distributions, it is necessary to enhance the culture soft power, carry on classic cultural industries, such as setting up paper-cutting museums and conducting woodcarving performances. In this doing, it is more conducive to develop local cultural industries, preserve non-material cultural heritages, increase employment rate, and induce the virtuous circle, so as to enhance people's sense of cultural identity and belonging, and forge humanistic towns with harmonious development.

\subsection{Enhance Cultural Infrastructure Construction, and People's Involvement}

The status of cultural infrastructure can reveal the level of civilization, humanistic connotations and urban competitiveness in a region. Perfecting the overall cultural infrastructure construction is the precondition to achieve common prosperity in cultural development and cause in Chinese characteristic towns, in order to form the atmosphere of "public involvement, culture sharing, cultural communication". In the meantime, with advanced development of Internet, cultural construction also needs to keep with up the latest trend, and publicize excellent cultural industries online. Specific measures include WeChat, Weibo, websites and Taobao, in order to constantly innovate online cultural development patterns.

\section{References}

Fuchao. (2016). Comparison and References of International References on Characteristic Town Development. China Economic \& Trade Herald, 2016(November), 34-35.

Hu, Z. C. (2016). National Economy, Social Development and 13th Five-Year-Planning Summary. China Economic \& Trade Herald, 2016(August), 6-15.

Li, Q. (2015). Promote Characteristic Town Construction with Reform and Innovation. Jinri Zhejiang, 2015(13), 8-10.

Li, W. J., \& Li, Y. (2015). Experience and Enlightenment on Planning and Design of Towns and Villages in the UK. Art Panorama, 2015(10), 100-101. 
Ma, L., Liang, H., \& Wang, B. X. (2013). Experience and Enlightenment on Adhering to the Development of Socialist Culture with Chinese Characteristics. Jiangsu Socialist Colleges Journal, 2013(06), 62-66.

Zhang, M. (2010). Classification of Non-material Cultural Heritage. Zhejiang University. 